\title{
Mercado interno para os produtos da floricultura brasileira: características, tendências e importância socioeconômica recente ${ }^{(1)}$
}

\author{
ANTONIO HÉLIO JUNQUEIRA ${ }^{(2)}$ e MARCIA DA SILVA PEETZ ${ }^{(3)}$
}

\begin{abstract}
RESUMO
A floricultura empresarial brasileira vem adquirindo notável desenvolvimento nos últimos anos e se caracteriza já como um dos mais promissores segmentos da horticultura intensiva no campo dos agronegócios nacionais. Observase, em todo o Brasil, um movimento marcado por fortes índices de crescimento da base produtiva e inclusão de novos pólos geográficos regionais na produção de flores e plantas ornamentais. Segundo estimativas, nos últimos anos, a atividade passou a agregar 5.152 produtores, os quais cultivam uma área de 8.423 hectares. A sustentação econômica essencial da atividade é garantida pelo vigor do mercado interno que atingiu, em 2007, a movimentação anual de US\$ 1,3 bilhão. As exportações, ainda que conquistando sucessivos recordes observados ao longo da presente década, ainda pouco ultrapassa a cifra U\$ 35 milhões em vendas anuais, ou o equivalente a 2,7 \% do valor total da produção, com crescentes embarques para a Holanda, EUA, Japão, Espanha, França e mais outros 30 diferentes destinos em todo o mundo. Apesar disso, o mercado interno de flores e plantas ornamentais no Brasil deve ser entendido no contexto dos padrões de consumo dos países em desenvolvimento, nos quais predominam: baixo índice de consumo per capita; mercado com pequeno número relativo de compradores freqüentes; compras centradas em produtos bastante tradicionais e forte concentração sazonal da demanda em datas especiais e comemorativas, como Dia das Mães, Finados, Namorados, entre poucas outras.
\end{abstract}

Palavras-chave: produção, distribuição atacadista, comércio varejista, consumo, flores e plantas ornamentais.

\author{
ABSTRACT \\ Inner market for the products of the Brazilian floriculture: characteristics, trends and recent social- \\ economic importance
}

Professional Brazilian floriculture is acquiring notable development in recent years and can be already characterized as one of the most promising segments of intensive horticulture in national agribusiness. It is observed, throughout the country, a movement marked with strong growth of its productive base indexes and the inclusion of new regions of flowers and ornamental plants production. According to estimates, in recent years, there are 5,152 producers, which cultivate an area of 8,423 hectares. The economic sustentation of this activity is guaranteed by the vigor of the domestic market reached in 2007 with the annual movement of US\$ 1.3 billion. The exports, despite achieving successive records observed throughout the present decade, still remain about U\$ 35 million in annual sales, or the equivalent $2.7 \%$ of the total value of the production. The main destinations are: Holland, U.S.A., Japan, Spain, France and other 30 different countries around the world. Despite that, the market of flowers and ornamental plants in Brazil must be understood in light of developing countries consumption patterns, in which predominates: low per capita consumption indexes; market with small relative number of frequent buyers; purchases centered in traditional products, and demand density is strongly seasonal and tied to special and commemorative dates, such as: as Mother's Day, Valentine's Day, All Souls’ Day, among others.

Key words: production, wholesale distribution, retailing, flowers and ornamental plants consumption.

\footnotetext{
${ }^{1)}$ Uma primeira versão deste trabalho foi preparada e apresentada pelos autores no Congresso Fiaflora Exporgarden de Floricultura 2005, realizado em Brasília / DF, no período de 25 a 27 de maio de 2005, como subsídio técnico para a elaboração do documento de diretrizes para a Câmara Setorial da Cadeia Produtiva de Flores e Plantas Ornamentais, cujos resultados finais, conforme aprovado em plenária pelas lideranças nacionais do setor, então reunidas, foram integralmente publicados (Cf. BRASIL, 2007; OPTIZ e BOQUADI, 2006). Recebido em 18/02/2008 e Aprovado em 19/03/2008.

Engenheiro Agrônomo, Especialista em Desenvolvimento Rural e Abastecimento Alimentar Urbano (FAO/PNUD), Mestrando em Comunicação e Práticas de Consumo - ESPM; Hórtica Consultoria e Treinamento; Caixa Postal 27028. CEP: 04007-970 - São Paulo (SP).

Economista, Especialista em Economia Rural, Abastecimento e Comercialização Agrícola; Hórtica Consultoria e Treinamento; Caixa Postal 27028. CEP: 04007-970 - São Paulo (SP).
} 


\section{INTRODUÇÃO}

Ao longo dos últimos anos, a floricultura empresarial brasileira vem adquirindo notável desenvolvimento e se caracteriza já como um dos mais promissores segmentos da horticultura intensiva no campo dos agronegócios nacionais. É nesse contexto, que se visualizam as importantes mudanças estruturais apontadas ao longo desta pesquisa e que sinalizam para o fato de que o Brasil caminha, decisivamente, para a implantação de um modelo de qualidade internacional de gestão e de governança de sua Cadeia Produtiva de Flores e Plantas Ornamentais. Nesse novo panorama estão sendo geradas inúmeras novas oportunidades de negócios e de inserção comercial competitiva, eficiente e sustentável para os pólos emergentes de produção distribuídos por todo o País.

Observa-se, em todo o Brasil, um movimento marcado por fortes índices de crescimento da base produtiva e inclusão de novos pólos geográficos regionais na produção de flores e plantas ornamentais. Esses fenômenos foram bastante bem-vindos nos primeiros anos de estabilidade econômica decorrente dos planos governamentais focados no controle da inflação, especialmente no final dos anos oitenta e início dos noventa. Porém, com a acomodação na dinâmica econômica interna nos anos mais recentes, o desafio de manter esses desejáveis índices de crescimento e, ao mesmo tempo, assegurar o escoamento das mercadorias, tornou-se dramaticamente prioritário na cadeia produtiva da floricultura.

A sustentação econômica essencial da atividade é garantida pelo vigor do mercado interno, visto que as exportações, ainda que conquistando sucessivos recordes observados ao longo da presente década, ainda pouco ultrapassa a cifra de U $\$ 35$ milhões em vendas anuais, ou o equivalente a $2,7 \%$ do valor total da produção, com crescentes embarques para a Holanda, EUA, Japão, Espanha, França e mais outros 30 diferentes destinos em todo o mundo (JUNQUEIRA e PEETZ, 2008).

Portanto, é o consumo interno que, efetivamente, sinaliza para as reais potencialidades de sucesso econômico e empresarial futuro da atividade. Nesse sentido, o adequado conhecimento das características, tendências e oportunidades nesse segmento, bem como sobre o poder de influenciar, estimular e orientar práticas que redundem no aumento de consumo se reveste de importância fundamental na cadeia produtiva de flores e plantas ornamentais contemporânea, como única maneira eficiente e eficaz de encontrar vazão para a crescente produção interna.

\section{PRINCIPAIS CARACTERÍSTICAS ESTRUTURAIS DAFLORICULTURABRASILEIRA}

A floricultura brasileira contemporânea possui muitas semelhanças tecnológicas e comerciais com a olericultura, especialmente quanto à utilização do cultivo protegido, substratos e condicionadores de solo, fertirrigação, entre outros aspectos. Costuma, inclusive, ser apontada como o segmento mais dinâmico da horticultura e, nesse sentido, indutora de mudanças, com reflexos importantes sobre o cultivo comercial de hortaliças.

Historicamente, contudo, suas raízes no Brasil vinculam-se ao segmento da fruticultura, no qual surgiram seus primeiros cultivos comerciais tanto no Estado de São Paulo (AKI e PEROSA, 2002), quanto em Santa Catarina (CASTÃN et al., 2006). De fato, no Estado de São Paulo, a floricultura originou-se como atividade secundária da fruticultura, a partir do trabalho de empresas tradicionais como Dierberger (1893) e Roselândia (1929). A floricultura com caráter comercial iniciou-se nesse Estado apenas na década de 50, e veio a consolidar-se e profissionalizar-se a partir da década de 70, com a fundação, pelos imigrantes holandeses e seus descendentes, da Cooperativa Agropecuária de Holambra, em 1972.

Desde a década de 50, até muito recentemente, a floricultura empresarial e comercial praticada no Brasil concentrou-se - com a exceção de bem poucos outros pólos produtivos - no Estado de São Paulo, particularmente nas regiões do entorno dos municípios de Atibaia e Holambra (AKI e PEROSA, 2002). A partir dessas regiões e sob a gestão comercial da Cooperativa Veiling Holambra, nas décadas de 70 e 80 organizaram-se e estruturaram-se fluxos de abastecimento de curta, média e longas distâncias, que perduram até os dias atuais e que lograram fazer chegar as flores e plantas ornamentais paulistas a praticamente todas as capitais e principais pólos de consumo de todo o País.

Como uma importante decorrência histórica dessa concentração verificada no Brasil - na qual poucos pólos de produção sustentam os fluxos de abastecimento de amplas faixas territoriais - assistiu-se, ao longo das últimas décadas, a uma notável homogeneização dos hábitos de consumo. Nesse processo, as flores e plantas regionais acabaram perdendo a importância e a preferência dos seus antigos consumidores, frente à qualidade, padrão e às ofertas abundantes e regulares dos produtos originados da floricultura mais profissional e competitiva das Regiões Sul e Sudeste do Brasil, especialmente daquelas produzidas e comercializadas pelos associados e produtores integrados à Cooperativa Veiling Holambra.

Assim, a despeito da enorme riqueza da flora e da cultura do País, o consumo de flores e plantas ornamentais passou a concentrar-se numa reduzidíssima pauta de produtos, praticamente indistinta desde o Sul até o Norte do Brasil (tabela 1). Esse fenômeno passou a ter uma redução de intensidade apenas nos últimos anos, permitindo observar um notável crescimento e consolidação de outros importantes pólos florícolas no Rio Grande do Sul, Paraná, Santa Catarina, Minas Gerais, Rio de Janeiro, Goiás, Distrito Federal e nos estados do Norte e do Nordeste do País.

Podem ser apontadas muitas razões que propiciaram o surgimento dessa nova realidade no campo da produção e do abastecimento das flores e plantas ornamentais em todo o território brasileiro, entre os quais se destacam: 
a) a necessidade de se buscarem novas alternativas produtivas e comerciais para as micro, pequenas e médias propriedades rurais, frente à perda de oportunidades de negócios e à alteração global dos padrões tecnológicos e da geografia da produção brasileira dos principais grãos, oleaginosas e café, da pecuária e da agricultura mais extensiva, de um modo geral (CROMBERG, 2002; JUNQUEIRA e PEETZ 2005a, 2006b);

b) os incentivos crescentes dados por governos estaduais e entidades de apoio e fomento para o fortalecimento de novas iniciativas produtivas ${ }^{4}$, especialmente no caso daquelas que, como a floricultura, se viabilizam em espaços exíguos de terra, gerando boas rentabilidades e relevantes quantidades de empregos tanto rurais quanto urbanos (JUNQUEIRA e PEETZ 2005a, 2006b; BRAINER e OLIVEIRA, 2007);

c) a abertura de novos canais e oportunidades comerciais no mercado externo, o que vem propiciando e incentivando a instalação e o desenvolvimento de uma floricultura tropical relativamente especializada nas Regiões Norte e Nordeste do Brasil, bem como na realocação geográfica de empresas tradicionais de alta tecnologia de São Paulo para outros pólos produtivos, especialmente no Estado do Ceará, de modo a usufruir de benefícios climáticos e de maior proximidade dos mercados consumidores de destino;

d) a necessidade de ajuste permanente dos preços finais aos consumidores, em um mercado restritivo e relativamente inflexível ao repasse de novos aumentos de custos, fazendo com que a otimização logística na distribuição se torne um objetivo primordial em toda a cadeia produtiva;

e) o crescente nível de exigência dos consumidores pela qualidade, durabilidade e frescor dos produtos, fazendo com que as produções mais proximamente localizadas passassem a adquirir uma maior valorização final nos mercados;

f) a intensificação dos processos de introdução e adaptação de novas espécies, cultivares e híbridos no País, facilitada pela regularização da Lei de Proteção de Cultivares, permitindo atualização permanente da floricultura nacional frente às principais tendências e lançamentos mundiais no segmento.

Frente à velocidade e intensidade desse novo quadro produtivo, o número de produtores e área cultivada na floricultura evoluiu muito rapidamente em todo o País, não sendo ainda devidamente captado por nenhuma fonte estatística oficial. Até o ano de 2004, as únicas estatísticas nacionais disponíveis haviam sido produzidas pelo IBRAFLOR, com base em levantamentos realizados em 2002 e 2003. Esse trabalho, porém, não teve natureza censitária e seus resultados foram parciais, condicionados à qualidade e intensidade da participação voluntária de produtores de todas as regiões do Brasil. A amostra trabalhada pelo Ibraflor abrangeu 1.356 produtores. Porém, a partir desses dados a entidade elaborou e divulgou estimativas que apontavam para a existência de cerca de quatro mil floricultores ativos no País (IBRAFLOR, 2004). Além disso, a pesquisa mostrou que, então, a floricultura já contabilizava uma área cultivada anual próxima de 5,2 mil hectares, distribuída em 304 municípios brasileiros (GRAZIANO, 2002).

Em 2004, o IBGE publicou suas primeiras estatísticas sobre o setor de flores e plantas ornamentais, baseadas, contudo, nos dados captados em 1995/1996 para a elaboração do Censo Agropecuário (IBGE, 2004). Os dados assim revelados eram muito maiores do que aqueles com os quais os técnicos e analistas do setor vinham até então trabalhando, o que veio a gerar muitos tipos de interpretação, de análises contraditórias e até mesmo

Tabela 1. Principais flores e plantas ornamentais comercializadas no Brasil, 2007

Table 1. Main flowers and ornamental plants sold in Brazil, 2007

\begin{tabular}{|c|c|c|}
\hline $\begin{array}{c}\text { Flores envasadas } \\
\text { Pot plants }\end{array}$ & $\begin{array}{c}\text { Plantas verdes envasadas } \\
\text { Houseplants }\end{array}$ & $\begin{array}{c}\text { Flores de corte } \\
\text { Cut flowers }\end{array}$ \\
\hline $\begin{array}{c}\text { Crisântemo } \\
\text { (Dendranthema grandiflorum) } \\
\text { Violeta } \\
\text { (Saintpaulia ionantha) } \\
\text { Calanchoe } \\
\text { (Kalanchoe blossfeldiana) } \\
\text { Begonia } \\
\text { (Begonia spp.) } \\
\text { Azaléia } \\
\text { (Rododendro sp.) } \\
\text { Orquídea } \\
\text { (Cattleya sp.; Dendrobium sp.; } \\
\text { Phalaenopsis sp e outros) } \\
\text { Bromélia } \\
\text { (Vriesea } \text { sp; Neoregelia sp e outros) } \\
\text { Lírio } \\
\text { (Lilium } \text { sp.) }\end{array}$ & $\begin{array}{c}\text { Ficus } \\
\text { (Ficus benjamina e outros) } \\
\text { Schefflera } \\
\text { (Schefflera arboricola) } \\
\text { Singônio } \\
\text { (Syngonium angustatum }) \\
\text { Samambaia } \\
\text { (Nephrolepsis sp e outros) } \\
\text { Tuia } \\
\text { (Chamaecyparis sp.) } \\
\text { Jibóia } \\
\text { (Epipremnum pinnatum) } \\
\text { Filodendro } \\
\text { (Philodendron) } \\
\text { comigo-ninguém-pode } \\
\text { (Dieffenbachia sp.) }\end{array}$ & $\begin{array}{c}\text { Rosa } \\
\text { (Rosa } \text { sp.) } \\
\text { Crisântemo } \\
\text { (Dendranthema grandiflorum) } \\
\text { Lírio } \\
\text { (Lilium } \text { sp.) } \\
\text { Gérbera } \\
\text { (Gerbera jamesonii) } \\
\text { Tango } \\
\text { (Solidago sp.) } \\
\text { Gladíolo } \\
\text { (Gladiolus hortulanus) } \\
\text { Aster } \\
\text { (Aster } \text { sp) } \\
\text { Gipsofila } \\
\text { (Gypsophila } \text { sp.) }\end{array}$ \\
\hline
\end{tabular}

Fonte: JUNQUEIRA e PEETZ, 2007a.

${ }^{(4)}$ Esse incentivo vem sendo garantido pela realização de estudos e pesquisas, programas de treinamento e capacitação técnica e profissional, promoção comercial, realização de feiras e eventos, missões técnicas e comerciais no Brasil e no exterior, entre outras ações de apoio e incentivo ao desenvolvimento sustentado da atividade. 
alguma polêmica. De qualquer forma, acreditou-se que a grande discrepância entre as estatísticas oficiais e as estimativas do mercado eram essencialmente devidas ao fato de que enquanto o IBGE havia contabilizado em seus números todos os produtores que tivessem auferido alguma renda a partir de produtos da floricultura, outras instituições e analistas contabilizavam apenas aqueles que possuíam integração comercial efetiva com o mercado (BRAINER e OLIVEIRA, 2007).

Hoje, números que representem até o dobro dessas quantidades são perfeitamente cogitáveis, enquanto aguarda-se que sejam, em breve, coletados e disponibilizados para o mercado e para os analistas novas estatísticas oficiais, por parte do IBGE ou de entidades representativas, como a Câmara Setorial da Cadeia Produtiva de Flores e Plantas Ornamentais do Brasil ou o Instituto Brasileiro de Floricultura (IBRAFLOR).

Assim, baseando-se em diversas fontes disponíveis, que em anos mais recentes vêm gerando informações parciais sobre a produção de flores e plantas ornamentais em âmbitos estaduais ou macro-regionais, foi possível elaborar a tabela 2 , na qual se contabilizou a existência de 5.152 produtores de flores e plantas ornamentais no Brasil.

Esse grupo de produtores brasileiros atualmente se distribui por cerca de 1.500 municípios (IBGE, 2002), cultivando uma área total estimada entre 8.423 hectares, conforme demonstrado na tabela 3 (BRAINER e OLIVEIRA, 2007) e 9.000 hectares (KIYUNA et al., 2002).
Ambas prospecções, contudo, são bastante superiores àquela recentemente divulgada pela Câmara Setorial da Cadeia Produtiva de Flores e Plantas Ornamentais, de 6.000 hectares (ANUÁRIO, 2007).

Segundo dados do Instituto Brasileiro de Floricultura, estima-se que a atividade responda pela geração, na média nacional, de 3,7 empregos diretos $/ \mathrm{ha}^{10}$, os quais vêm a equivaler a 12,95 empregos numa propriedade dedicada à floricultura, já que a área média da unidade produtiva na floricultura brasileira é de 3,5 ha. Ressalte-se, ainda, que 94,4\% desses empregos são preenchidos com mão-de-obra permanente, essencialmente contratada $(81,3 \%)$, enquanto que o trabalho familiar responde por $18,7 \%$ do total empregado, caracterizandose, assim, o seu inquestionável papel e importância sócioeconômica. (GRAZIANO, 2002).

No Nordeste brasileiro, em 2005, constatou-se a utilização média de 19,02 trabalhadores por unidade produtiva, sendo $89,60 \%$ permanentes e $10,40 \%$ temporários. Considerando que essas unidades contam com área média de 1,73 ha cultivado com floricultura, conclui-se pelo emprego de 10,99 trabalhadores por hectare, sendo 9,85 permanentes. Da mão-de-obra permanente utilizada, a familiar correspondia a $8,61 \%$ e a assalariada a $91,39 \%$, com predominância de remuneração na faixa de um a dois salários mínimos mensais (BRAINER e OLIVEIRA, 2007:186).

No Brasil, a produção é desenvolvida em pequenas propriedades, cuja média nacional de área

Tabela 2. Estimativa do número de produtores de flores e plantas ornamentais do Brasil, por macro-regiões geográficas, em 2007

Table 2. Estimate number of producers of flowers and ornamental plants in Brazil, by macro- regions, 2007

\begin{tabular}{|c|c|c|c|}
\hline \multirow{2}{*}{$\begin{array}{c}\text { Macro-região geográfica } \\
\text { Macro-regions }\end{array}$} & \multicolumn{3}{|c|}{$\begin{array}{l}\text { Número de produtores } \\
\text { Number of producers }\end{array}$} \\
\hline & $\begin{array}{c}\text { Segundo IBGE } \\
(1995 / 96)\end{array}$ & $\begin{array}{c}\text { Segundo estimativas } \\
\text { BNB/ETENE } \\
(2004)^{(6)} \\
\end{array}$ & $\begin{array}{c}\text { Segundo atualizações por } \\
\text { diversas fontes } \\
(2002 / 2007)^{(7)}\end{array}$ \\
\hline $\begin{array}{l}\text { Norte } \\
\text { North }\end{array}$ & 122 & 272 & 272 \\
\hline $\begin{array}{l}\text { Nordeste } \\
\text { Northeast }\end{array}$ & 1.766 & 902 & 902 \\
\hline $\begin{array}{c}\text { Centro-Oeste } \\
\text { Center-West }\end{array}$ & 131 & 157 & 157 \\
\hline $\begin{array}{l}\text { Sudeste } \\
\text { Southeast }\end{array}$ & 2.555 & 2.689 & 2.689 \\
\hline $\begin{array}{l}\text { Sul } \\
\text { South }\end{array}$ & 2.953 & 1.132 & 1.132 \\
\hline Total & 7.527 & 5.152 & 5.152 \\
\hline
\end{tabular}

Fonte: JUNQUEIRA e PEETZ, com base em informações de: (5) IBGE (Censo Agropecuário 1995/1996, tabulações especiais, apud KIYUNA et al., 2002); (6) BRAINER e OLIVEIRA, 2007; (7) DAUDT (2002); IBRAFLOR (apud GRAZIANO, 2002); JUNQUEIRA e PEETZ (2005a, 2006b, 2007 $\mathrm{c}^{(8)} ; 2007 \mathrm{~d}^{(9)}$ ); RIO DE JANEIRO (2004); ESPÍRITO SANTO (2004); SEBRAE/AL (2004).

\footnotetext{
${ }^{(8)}$ JUNQUEIRA, A.H. e PEETZ, M.S. Acesso a Mercados: Perfil Mercadológico das Empresas. Projeto de Fortalecimento do Setor de Flores e Plantas Ornamentais do Estado do Espírito Santo. SEBRAE/ ES. Palestras apresentadas em Venda Nova do Imigrante/ES, em 26 abr. 2007 e em Vitória/ES, em 11 jul. 2007.

JUNQUEIRA, A.H. e PEETZ, M.S. Estudo da Competitividade e Eficiência da Cadeia Produtiva de Flores e Plantas Ornamentais na Região Norte do Brasil - Amazônia (resultados preliminares). SEBRAE /AM. Palestras setoriais apresentadas em Belém / PA; Boa Vista/RR; Macapá /AP; Manaus / AM; Palmas /TO; Porto Velho /RO e Rio Branco /AC, no período de 5 nov. a 11 dez. 2007.

Os dados obtidos empiricamente por diversos autores e instituições de pesquisas para diferentes estados, Distrito Federal e macro-regiões geográficas, exceto aqueles apontados, no texto, para a Região Nordeste, são, em realidade, bastante similares: 3,8 empregos/ha (IBRAFLOR, para a média da floricultura paulista, 2002); 3,6 empregos/ha (FRANCISCO et al., para a média da floricultura paulista, 2003a, 2003b); 3,1 empregos/ha (JUNQUEIRA e PEETZ, para a média da floricultura do Distrito Federal, 2005b).
} 
cultivada é de 3,5 hectares. Contudo, existem diferenças regionais importantes. Assim, o Estado de Goiás, por exemplo, possui uma área média de cultivo - a maior nacional - de 6,3 hectares, o que se explica pelo fato da sua vocação para a produção de mudas de plantas ornamentais, exigentes em maiores dimensões físicas de área.

Na Região Nordeste, pesquisas realizadas em 2005 constataram que a área média cultivada com flores e plantas ornamentais é de 1,73 ha por produtor e que esse valor correspondia, em média, a 8,61\% da área total da propriedade. As propriedades com menos de cinco hectares plantados com flores correspondiam a 70,2\% do total; as com cinco a dez representaram $19,15 \%$ e as com mais de dez, 10,65\% (BRAINER e OLIVEIRA, 2007:172).

Em todo o País, a distribuição da área cultivada com flores e plantas é de 50,4\% para mudas; $13,2 \%$ para flores envasadas; $28,8 \%$ para flores de corte; $3,1 \%$ para folhagens em vasos; $2,6 \%$ para folhagens de corte e $1,9 \%$ para outros produtos da floricultura (GRAZIANO, 2002).

Ainda segundo o IBRAFLOR, em toda a cadeia produtiva, são gerados 120 mil empregos, dos quais 58 mil $(48,3 \%)$ estão localizados na produção; 4 mil $(3,3 \%)$ na distribuição; 51 mil $(42,5 \%)$ no comércio varejista e sete mil $(5,9 \%)$ em outras funções, principalmente nos segmentos de apoio.

\section{DIMENSÕESECONÔMICASDOMERCADO INTERNO}

As dificuldades de obtenção e consolidação de estatísticas oficiais e consensuais sobre a dimensão do mercado brasileiro de flores e plantas ornamentais têm sido apontadas e discutidas por diversos pesquisadores (CROMBERG e CARLETTI, 2001; KIYUNA et al., 2002b).

Porém, com base na movimentação financeira efetiva da comercialização, em 2007, pela Cooperativa Veiling Holambra, pela CEAGESP e pelo Mercado Permanente de Flores e Plantas da CEASA Campinas principais centros atacadistas do País- e das correspondentes e adequadas projeções para o varejo e consumo final, pode-se afirmar com segurança que a floricultura brasileira movimenta, anualmente, no seu mercado doméstico, um valor global em torno de US\$1,3 bilhão. Dado, aliás, recentemente confirmado pela Câmara Setorial da Cadeia Produtiva de Flores e Plantas Ornamentais (ANUÁRIO, 2007). Assim, considerando que a população brasileira em 2007, segundo o IBGE atinge 183,9 milhões de pessoas, o consumo aparente gira em torno de US\$ 7 per capita. Acredita-se, contudo, que o potencial de vendas seja, pelo menos, equivalente ao dobro do atual, desde que superadas as restrições geradas por aspectos econômicos e culturais de amplas parcelas da população, além da superação de entraves logísticos importantes ao longo da cadeia produtiva.

Tabela 3. Estimativa da área cultivada com flores e plantas ornamentais no Brasil, por macro-regiões geográficas, em 2005.

Table 3. Flowers and ornamental plants estimate cultivated area in Brazil, by macro-regions, in 2005.

\begin{tabular}{cc}
\hline $\begin{array}{c}\text { Macro-região geográfica } \\
\text { Macro-regions }\end{array}$ & $\begin{array}{c}\text { Área cultivada (ha) } \\
\text { Cultivated area }\end{array}$ \\
\hline $\begin{array}{c}\text { Norte } \\
\text { North } \\
\text { Nordeste } \\
\text { Northeast } \\
\text { Centro-Oeste } \\
\text { Center-West } \\
\text { Sudeste } \\
\text { Southeast } \\
\text { Sul } \\
\text { South }\end{array}$ & 854 \\
Total & 260 \\
\hline
\end{tabular}

Fonte: BRAINER e OLIVEIRA, 2007

Tabela 4. Estimativa média do valor das vendas anuais e da participação relativa na agregação de valor, por segmentos da cadeia produtiva da floricultura no Brasil, 2007

Table 4. Average estimate of annual sales and relative added-value participation, by segments of floriculture market in Brazil, 2007

\begin{tabular}{ccc}
\hline $\begin{array}{c}\text { Segmento da cadeia produtiva da floricultura } \\
\text { Sector }\end{array}$ & $\begin{array}{c}\text { Participação na agregação de valor } \\
\text { Added-value (\%) }\end{array}$ & $\begin{array}{c}\text { Valor anual de vendas } \\
\text { Annual Sales (US\$ 1.000) }\end{array}$ \\
\hline Varejo e Serviços & PV = 3,5 a 4,0 vezes PP & $1.300 .000,00$ \\
Retail & PA= 1,5 a 1,8 vezes PP & $=487.500,00 \mathrm{a}=668.571,43$ \\
Atacado & $\mathrm{PP}$ & $=325.000,00 \mathrm{a}=371.428,57$ \\
Wholesale & & \\
Produtor & & \\
Producers & & \\
\hline
\end{tabular}

Fonte: JUNQUEIRA e PEETZ, com base em informações de empresas do mercado.

$\mathrm{PP}=$ preços recebidos pelos produtores / Producer price

$\mathrm{PA}=$ preços no atacado / Wholesale price

$\mathrm{PV}=$ preços no varejo / Retail price 
Os principais mercados atacadistas estão concentrados no Estado de São Paulo, envolvendo milhares de agentes e movimentando, anualmente, entre US\$ 487,50 milhões a US\$ 668,57 milhões (tabela 4). Ressalte-se que alguns desses mercados incorporam as mais modernas técnicas de comercialização, tais como o sistema de leilões próprios do modelo Veiling holandês e a comercialização eletrônica de mercadorias (Floranet / Cooperflora), destacando-se de todo o restante da horticultura comercial no Brasil.

Em termos de faturamento, as flores em vaso representam $50 \%$ da movimentação na cadeia produtiva, as flores de corte, $40 \%$ e as plantas verdes, $10 \%$, não incluindo aí as gramas, palmeiras, árvores e arbustos para paisagismo e jardinagem, para as quais, lamentavelmente, não existem estatísticas disponíveis (IBRAFLOR, 2004).

\section{PRINCIPAIS FORMAS DE COMERCIALIZAÇÃO NOMERCADOINTERNO}

\subsection{No setor atacadista}

A comercialização atacadista formalmente organizada de flores e plantas ornamentais no Brasil é concentrada em cerca de $90 \%$ no Estado de São Paulo ${ }^{11} 1$, sendo realizada prioritariamente pela Cooperativa Veiling Holambra (Holambra), seguida da CEAGESP (São Paulo), pelo Mercado Permanente de Flores e Plantas Ornamentais da Ceasa Campinas (Campinas), Floranet / Cooperflora (Holambra) e outros. Há que se observar, contudo, que desde o início da década até o ano de 2006, o Mercado Permanente de Flores e Plantas Ornamentais da Ceasa Campinas comercializou volumes e valores consideravelmente superiores aos da CEAGESP. Em 2007, excepcionalmente, constatou-se que o mercado paulista viveu um notável processo de revitalização, voltando à segunda posição no ranking do atacado, posição que ocupava, efetivamente, até o final da década de 1990 (tabela 5).

A comercialização das flores e plantas ornamentais brasileiras, com base no comportamento dos principais mercados atacadistas e empresas exportadoras, em 2007, pode ser distribuída na seguinte composição: Região Sudeste, 78,0\%; Região Sul, 13,1\%; Região CentroOeste, 3,6\%; Regiões Norte e Nordeste, 2,6\% e exportações, 2,7\% (Cf. JUNQUEIRA EPEETZ, 2007a).
No País, os produtores procuram estabelecerse isoladamente no processo de comercialização, com exceção apenas do pólo produtor de Holambra, onde o senso de organização da comercialização é um hábito cultural herdado dos imigrantes holandeses. Os centros de referência e principais mercados são, nesses casos, representados pelas Ceasas existentes nas capitais dos Estados e nas principais cidades e regiões metropolitanas de todo o País.

A desorganização na base produtiva impede uma evolução maior do setor, uma vez que não existem governança e coordenação empresarial dessas cadeias de produção e escoamento, o que leva a indesejáveis conseqüências tais como: falta de padrões de classificação e qualidade; ausência de transparência na formação de preços; falta de confiabilidade; elevado índice de inadimplência e surgimento de estruturas intermediárias, que fazem o papel de conduzir esse mercado (BONGERS, 2002).

Uma comercialização eficiente exige logística adequada, incluindo técnicas e operações de transporte, estocagem, comunicação com os clientes e compradores e a transferência de posse das mercadorias. Na cadeia de suprimento nacional, predominam, ainda, importantes estrangulamentos, especialmente no que se refere a transporte e acondicionamento de flores e plantas ornamentais sem o uso das câmaras frias, a utilização de caminhões sem isolamento térmico, além de depósitos inadequados. Ressalta-se, finalmente, a falta de mão-deobra especializada e de conhecimentos sobre as necessidades e exigências no trato pós-colheita adequado desses produtos, de natureza delicada.

Não existe uma única e melhor forma de comercialização. Cada país, de acordo com sua cultura e seu mercado, adota um modelo. A Holanda, como maior centro produtor e exportador do mundo, comercializa mais de $80 \%$ de sua produção através de leilões diários (Veiling), tornando-se assim o principal centro formador de preços do mercado europeu. Já nos EUA, que importam cerca de $40 \%$ do que consomem, a comercialização é direta desses importadores para os pontos de venda e, quase sempre, redes de supermercados fecham contratos com grandes

Tabela 5. Valor e quantidade de flores e plantas ornamentais comercializados pela CEAGESP, 2004 - 2007 Table 5. Value and amount of flowers and ornamental plants sold by CEAGESP, 2004 - 2007

\begin{tabular}{ccc}
\hline Ano & Valor Comercializado & $\begin{array}{c}\text { Quantidade } \\
\text { Amount }(\mathrm{t})\end{array}$ \\
\hline 2004 & $51.600 .000,00$ & 28.342 \\
2005 & $63.508 .245,08$ & 33.045 \\
2006 & $75.396 .608,81$ & 30.542 \\
$2007^{(12)}$ & $169.198 .214,79$ & 50.366 \\
\hline
\end{tabular}

Fonte: JUNQUEIRA e PEETZ, a partir de dados da CEAGESP / Departamento de Economia e Desenvolvimento (vários anos)

\footnotetext{
(11) Considera-se que o atacado formalmente organizado não inclui as vendas diretas nas zonas de produção particularmente relevantes no caso das plantas ornamentais para paisagismo e jardinagem. Nestes casos, predomina a aquisição de grandes quantidades de mercadorias diretamente junto aos produtores por agentes quase sempre informais do mercado (os chamados "linheiros"). Essas relações comerciais são muito relevantes junto aos pólos produtivos de plantas ornamentais de Goiás, Paraná, Santa Catarina, Rio Grande do Sul e Minas Gerais, particularmente na região do município de Dona Euzébia.

Embora parte da expansão comercial contabilizada pelo entreposto possa ser atribuída ao aumento do número dos produtos incluídos na listagem de acompanhamento estatístico, comprovou-se, de fato, um notável aumento de vendas ao longo do ano.
} 
produtores nacionais e/ou internacionais. Os principais formatos de atacado hoje vigentes no Brasil são discriminados a seguir e sua aplicação nos principais centros de comercialização, na tabela 6:

\section{a) Leilão}

O sistema de vendas via leilões, largamente difundido na Holanda, no Brasil somente ocorre na Cooperativa Veiling Holambra, responsável por cerca de $30 \%$ do comércio nacional de flores e plantas ornamentais. Sua introdução no Brasil foi feita pela Cooperativa Agropecuária Holambra, em 1989. É um sistema que permite uma mais justa formação de preços e a venda de grandes quantidades de produtos em um curto espaço de tempo, com manutenção da qualidade dos produtos. Totalmente informatizado, possibilita transparência nas transações comerciais. É referencia de preços para todo mercado nacional. O Veiling Holambra atingiu vendas de 188 milhões de unidades de vasos e maços de flores de corte em 2007, contra 128 milhões, em 2004 e 106 milhões vendidos em 2003. São diversos os tipos de compradores autorizados a freqüentarem o Veiling: a) despachantes (que realizam as operações de compra e despacho de mercadorias sob encomenda dos clientes, porém transferindo as operações de recebimento e desembaraço aos compradores no destino final); b) comissionários/ "corretores" (que apenas realizam as compras, mediante o recebimento de uma percentagem sobre o valor total adquirido, transferindo a responsabilidade pela execução das tarefas de retirada, despacho e transporte das mercadorias aos clientes); c) atacadistas de linhas/"linheiros" (que cobrem rotas pontoa-ponto em todo o País); d) cash and carry (redes supermercadistas que mantêm estoques para posterior revenda a outros atacadistas, com sede dentro do próprio Veiling) e e) clientes finais (varejo e serviços) (Cf. CASTRO, 1998: 28). Recentemente, os atacadistas que revendem os produtos para floriculturas e feiras respondem por $49 \%$ dos negócios do Veiling, enquanto centrais de abastecimento como a CEAGESP, empatando com os supermercados, ficam com $23 \%$ cada uma. O restante é dividido entre garden centers, decoradores e importadores. informais)

b) Contratos de intermediação (formais e

É um sistema em que produtores e distribuidores fecham contratos de curto, médio ou longo prazos, formais ou informais. Os preços, características do produto e prazos de entrega são acertados no fechamento dos contratos. Funciona como uma espécie de garantia, pois o produtor pode programar melhor sua produção, enquanto o cliente pode antecipadamente fixar seus preços para o varejo, principalmente em períodos que antecedem as principais datas de venda do setor, como Dia das Mães, Dia dos Namorados, Finados e Natal.

\section{c) Comercialização virtual}

Funciona basicamente como um banco de dados informatizado sobre os produtos disponíveis. O sistema é alimentado por produtores, que disponibilizam informações sobre quantidade, qualidade, preço e prazo de entrega. Os clientes, por sua vez, consultam estas informações por meio da internet ou então via terminais fixos, ficando informados sobre várias ofertas e podendo fechar negócios. Sistema atualmente operando na Cooperativa Veiling Holambra e na Cooperflora.

\section{d) Centrais de Abastecimento S/A (CEASAS)}

A comercialização de flores e plantas ornamentais via Ceasas iniciou-se no Brasil com a criação da Companhia de Entrepostos e Armazéns Gerais do Estado de São Paulo (CEAGESP), em 1969. Posteriormente, outros centros atacadistas foram introduzidos no interior do Estado de São Paulo, nesta mesma empresa. Em 2007, o mercado atacadista do Entreposto Terminal de São Paulo, da CEAGESP, ocupou a segunda posição na movimentação global dos produtos da floricultura, tendo voltado a superar o Mercado Permanente de Flores e Plantas Ornamentais da Ceasa Campinas.

É o sistema de comercialização mais antigo e tradicional, em que os produtores ficam um ao lado do outro, oferecendo sua produção aos clientes. Esse sistema é conhecido como venda "na pedra". São espaços de 20 a $50 \mathrm{~m}^{2}$ cada, onde os produtos ficam expostos sob condições precárias. Operam entre uma a duas vezes por semana "na pedra" e outras uma ou duas vezes ao "ar livre", ou sobre caminhões, atendendo tanto clientes atacadistas e varejistas, como consumidores finais.

e) Centrais de Distribuição e Comercialização de Flores e Plantas Ornamentais

Compõem-se de equipamentos surgidos nos últimos anos e que visam suprir as necessidades da comercialização atacadista setorial em estados ou municípios onde não existem CEASAS ou onde estas não possuíam esse tipo de atacado nas suas estruturas funcionais próprias. Em alguns casos, representam a iniciativa de grupos de produtores, associações ou cooperativas interessados em ofertar e gerir a comercialização atacadista (e eventualmente também varejista) de seus produtos. Esses entrepostos ou centrais podem vir a ser criados e administrados autonomamente, pelo setor privado, ou implantados e co-geridos pela administração pública, geralmente contando com a participação das CEASAS dos estados onde se instalam. São exemplos das iniciativas contempladas no primeiro caso: O Mercaflor (Joinville / SC) e a Central de Negócios SP Flores, da Cooperativa Agrícola Flores de São Paulo (Arujá/SP); e do segundo: a Central de Distribuição e Comercialização de Flores e Plantas Ornamentais do Rio Grande do Sul (Porto Alegre/RS). Ressalte-se que alguns equipamentos comerciais criados ou estimulados por associações de produtores acabaram efetivamente se estabelecendo no ramo varejista. São os casos, por exemplo, da Central Flores, administrada pela Associação Brasiliense dos Produtores de Flores e Plantas Ornamentais (Brasília/DF) e do Mercado do Ogunjá, em Salvador/BA, resultado de uma ação conjunta entre o governo do Estado da Bahia e a Associação Baiana dos Produtores de Flores e Plantas Ornamentais (ASBAFLOR).

A cidade de São Paulo deverá contar em 2008 também com um mercado privado de flores e plantas 
ornamentais voltado tanto para o atacado quanto para o varejo. $\mathrm{O}$ empreendimento deverá ser construído, gerido e explorado economicamente por uma empresa privada (Construtora Marquise, vencedora da licitação da Prefeitura Municipal de São Paulo, em setembro de 2007) e contará com $76 \mathrm{mil} \mathrm{m}^{2}$, sendo 14,2 mil $\mathrm{m}^{2}$ de área útil de comercialização, com 310 boxes/lojas e com um faturamento previsto de R $\$ 5$ milhões/mês.

\subsection{No setor varejista}

A distribuição varejista de flores e plantas ornamentais em todo o Brasil conta com cerca de $20 \mathrm{mil}$ pontos de venda. O Estado de São Paulo concentra a maior parcela dessas lojas, já que representa perto de $50 \%$ de todo o consumo nacional ${ }^{13}$, enquanto que apenas a cidade de São Paulo absorve algo em torno de $25 \%$ de toda a demanda brasileira de flores e plantas ornamentais.

Atualmente, observam-se grandes movimentos de alteração na participação relativa dos equipamentos e canais de distribuição no varejo. Assim, as alternativas mais modernas e dinâmicas da distribuição, capazes de inovar e fornecer diferenciais significativos não apenas de preços, mas também de comodidade, conforto e conveniência, como os supermercados e garden centers, vêm conquistando rapidamente maiores fatias do mercado, mas em algumas circunstâncias e regiões específicas podem se dar às custas de um menor resultado relativo de vendas dos equipamentos e canais mais tradicionais, como as floriculturas e feiras-livres.

De modo geral, o varejo brasileiro de autoserviços tende a seguir as tendências e as inovações tecnológicas e comercias do mercado norte-americano. Com base nessa constatação, é justificável acreditar que as vendas de flores e plantas ornamentais no canal supermercadista no Brasil saltarão, num futuro breve, da atual faixa de $9 \%$ a $10 \%$ para $23 \%$ do total do mercado, conforme já ocorre nos EUA desde 2004 (tabela 7).

Tabela 6. Formas de comercialização vigentes nos principais mercados atacadistas de flores e plantas ornamentais do Estado de São Paulo, em 2007

Table 6. Current commercialization forms in main wholesale markets of flowers and ornamental plants of the State of São Paulo, in 2007

\begin{tabular}{ccccc}
\hline Mercado Atacadista & & \multicolumn{2}{c}{$\begin{array}{c}\text { Atacado tradicional } \\
\text { Tradional wholesale }\end{array}$} \\
\cline { 3 - 5 } Wholesale market & Leilão & Venda virtual & Intermediação & Venda na pedra \\
& Auction & On line & by wholesalers & by producers \\
\hline Cooperativa Veiling Holambra & $\mathrm{X}$ & $\mathrm{X}$ & $\mathrm{X}$ & \\
Cooperflora & & $\mathrm{X}$ & $\mathrm{X}$ & \\
Ceasa Campinas & & $\mathrm{X}$ & $\mathrm{X}$ \\
CEAGESP São Paulo & & $\mathrm{X}$ & $\mathrm{X}$ \\
SP Flores - Arujá & & $\mathrm{X}$ & $\mathrm{X}$ \\
\hline
\end{tabular}

Fonte: JUNQUEIRA e PEETZ, a partir de atualização de informações da Câmara Setorial de Floricultura do Estado de São Paulo.

Tabela 7. Participação relativa dos pontos-de-venda na comercialização de flores e plantas ornamentais nos mercados de diversos países da Europa e dos EUA, em 2004

Table 7. Market shares by sellers of flowers and ornamental plants in selected countries and regions in Europe and U.S.A., in 2004

\begin{tabular}{ccc}
\hline $\begin{array}{c}\text { Países / Regiões } \\
\text { Selected Countries / Regions }\end{array}$ & $\begin{array}{c}\text { Equipamentos tradicionais } \\
\text { Traditional outlet }^{(14)} \\
(\%)\end{array}$ & $\begin{array}{c}\text { Varejo de auto-serviço } \\
\text { Retailers }^{(15)} \\
(\%)\end{array}$ \\
\hline Holanda / Netherlands & 44 & 24 \\
Alemanha / Germany & 54 & 15 \\
Reino Unido / United Kingdon & 27 & 58 \\
França / France & 67 & 13 \\
Suíça / Swtizerland & 28 & 51 \\
Itália / Italy & 73 & 4 \\
Europa (Média) Europe (average) & 55 & 21 \\
EUA/USA & 56 & 23 \\
\hline
\end{tabular}

Fonte: Flower Council of Holland, apud VLIET $^{16}(2005)$

\footnotetext{
${ }^{(13)}$ Encontra-se freqüentemente na literatura estimativas que apontam para uma participação relativa do Estado de São Paulo, em nível de varejo, na faixa de 50\% (ANUÁRIO, 2007), 60\% (SEBRAE / RJ, 2003) a até 70\% (KIYUNA et al., 2002b), do consumo nacional global de flores e plantas ornamentais. Considerou-se, nessa pesquisa, o índice mais conservador como adequado à realidade atual do mercado da floricultura brasileira.

Flower shop, street market and direct sales producers to consumers.

Supermarket, hypermarket, department stores discounters, chain of garden centers, Do-It-Yourself (DIY) stores, chains of flower store and petrol stations.

${ }^{16}$ VLIET, C. v. (Flower Council of Holland). Market developments, segmentation and consequences for producers on the international flower's market. Palestra apresentada no Congresso Fiaflora Expogarden Brasília 2005 de Floricultura, Brasília, 26 e 27 de maio de 2005.
} 


\section{a) Varejo tradicional}

É representado principalmente pelas floriculturas, presentes em praticamente todas as cidades do País. Completam o rol desses canais as feiras-livres, que são particularmente importantes no município de São Paulo e o comércio ambulante, que, na maioria dos casos, opera apenas sazonalmente por ocasião das datas especiais, notadamente Dia das Mães e Finados.

\section{b) Varejo supermercadista}

As principais lojas e redes de supermercados em todo o País já oferecem flores em suas lojas. Especificamente para o Veiling Holambra, os supermercados já respondem, em média, por $23 \%$ das vendas totais de buquês e flores em vasos, sendo que até 2004, tais vendas podiam ser consideradas insignificantes. Analistas do mercado acreditam que não houve uma substituição do canal de compra, mas sim uma verdadeira expansão da clientela. $\mathrm{O}$ crescimento anual estimado nos últimos anos tem-se situado na faixa entre $10 \%$ e $20 \%$. Os preços praticados nos supermercados são considerados altamente competitivos e a exposição de flores e plantas logo na entrada das lojas favorece as compras por impulso, característica importante no consumo dessas mercadorias ${ }^{17}$. Como o auto-serviço age como um estimulador de novos hábitos de consumo e os brasileiros ainda não são grandes consumidores de flores e plantas ornamentais, o setor tem grandes expectativas para o futuro. Para o setor de auto-serviços, os negócios da floricultura passaram a ser vistos como oportunidade, porque se referem a uma categoria de produtos na qual não predominam as guerras de preços entre lojas e equipamentos, além de disponibilizarem grandes variedades de mercadorias e de suas formas de apresentação ao cliente. Os produtos podem ser expostos em diversas situações, com diferentes valores agregados (embalagens decorativas, cachepots e outros acessórios, por exemplo), servindo ao cross merchandising e/ou impulsionadores de vendas nas datas comemorativas. Certamente ainda há muito trabalho a ser feito no merchandising dessas mercadorias, expondo-as de forma mais bem organizada e cuidada, utilizando conceitos eficientes como o de verticalização (inclusive por faixas cores), criando espaços adicionais com ilhas em vários setores da loja, interceptando os clientes e provocando vendas por impulso. Acredita-se que, nos próximos anos, o segmento de auto-serviços não apenas conquistará os clientes que já possuem hábitos de consumir regularmente flores e plantas e formará, mas que também desenvolverá novos consumidores, porque oferece produtos diferenciados a preços acessíveis a todas as classes sociais, proporcionando aumento no valor do ticket médio de compra (MONTEJANO, 2005).

\section{c) "Garden centers"}

Constituídos por lojas especializadas na comercialização de flores e plantas ornamentais e todos os demais itens necessários às atividades do paisagismo e da jardinagem. Costumam incluir uma ampla e diversificada gama de mercadorias como vasos, substratos, adubos, ferramentas, mobiliários e acessórios para jardins e decoração de interiores e exteriores, fontes, pedras, estátuas etc. Normalmente, agregam também a oferta de serviços de paisagistas, jardineiros profissionais, decoradores, técnicos em irrigação e outros, próprios e/ou conveniados com as lojas. Parte do recente e ampliado sucesso desses equipamentos comerciais está na oferta, além dos serviços, também de comodidades e conveniência, como grandes espaços para estacionamento de veículos e movimentação de cargas.

\section{d) "Varejo on line"}

A concentração do varejo on line em geral é bastante acentuada, pois estima-se que apenas 25 empresas detenham cerca de $70 \%$ do mercado e, para competir, é preciso ter diferenciais significativos. De um modo geral, considera-se que a criação de um negócio virtual dissociado do negócio real, principalmente no caso das floriculturas, é difícil para o pequeno empresário. $\mathrm{O}$ varejo on line movimenta perto de $\mathrm{R} \$ 2,3$ bilhões por ano no Brasil. Desse total, em 2005, o setor de floriculturas participou com vendas de quase $\mathrm{R} \$ 40$ milhões (tabela 8). Em 2001, a compra e venda de flores pela rede tiveram faturamento de $\mathrm{R} \$ 1,4$ milhão, o equivalente a apenas $0,3 \%$ do total do varejo on line do País. Em 2005, estima-se que esse percentual elevou-se para próximo de 2,0\%. (BRANCHER, 2005).

Entre os fatores de sucesso recente dessa atividade, devem-se relacionar os investimentos na profissionalização e na conquista da confiança do consumidor, a partir da pontualidade da entrega, conveniência, sigilo das informações bancárias e facilidades de pagamento, bem como o estabelecimento de parcerias estratégicas com fabricantes e fornecedores de itens correlatos, como bombons, chocolates, CDs, vinhos e bebidas finas, aromas, bichos de pelúcias etc. Os aspectos tecnológicos ligados à operacionalização e facilidade de navegação nos sites de compra também podem ser apontados como aspectos decisivos para o crescimento da importância setorial.

A administração do negócio virtual difere dos modelos tradicionais utilizados pelas lojas físicas pelas suas características de distribuição, já que, ao contrário das lojas comuns, os agentes do comércio eletrônico têm a opção de trabalhar praticamente sem estoques de mercadorias. Para a entrega das encomendas, as lojas

\footnotetext{
(17) O comportamento impulsivo do consumidor tem sido incentivado por meio de múltiplas ações de marketing, entre as quais se destaca a própria política de localização do setor no interior das lojas. Anteriormente, as flores e plantas ornamentais eram comercializadas no setor de bazar, por se associarem aos produtos de jardinagem, como vasos, substratos, adubos etc. Porém, a partir do entendimento comercial das vantagens da sua agregação ao grupo de vegetais perecíveis, os produtos da floricultura foram transferidos para o setor de frutas, legumes e verduras (FLV). Assim, conquistaram as vantagens de poder usufruir de um maior fluxo e circulação de compradores, do aproveitamento dos profissionais mais bem capacitados no manuseio de perecíveis, além da melhor exposição e apresentação ao consumidor final, que, no conjunto, resultaram em expansão dos resultados de vendas (Cf. MONTEJANO, 2005).
} 
podem se utilizar de modalidades diferentes de remessas, que incluem tanto os serviços prestados pelos Correios quanto o de empresas transportadoras convencionais. Também, para o atendimento de localidades distantes e vendas para o exterior, a floricultura on line utiliza-se do apoio de floriculturas regionais conveniadas, as quais, por sua vez, efetivamente dispõem de lojas físicas e de estoques de mercadorias.

O setor do varejo on line de flores no Brasil ainda é muito concentrado, pois cerca de dez floriculturas concentram aproximadamente $90 \%$ de todo o mercado. Uma floricultura on line bem-sucedida costuma operar com cerca de 300 a 350 pedidos eletrônicos por mês.

A venda de flores pela internet segue o calendário do varejo tradicional e é centrada em datas de pico, como Dia das Mães e Dia dos Namorados, além do Natal, Réveillon e outras. Já no Natal de 2004, as flores apareceram em quinto lugar entre os produtos mais comercializados pela rede, com $1 \%$ do total, atrás apenas de CDs, DVDs e vídeos (29\%), eletrônicos (15\%), livros, revistas e jornais $(13 \%)$ e itens de saúde e beleza (6\%). Atualmente, os negócios on line representam uma das mais fortes tendências para o crescimento dos negócios no ramo da floricultura e para a conquista de novos clientes.

\section{CARACTERÍSTICASE TENDÊNCIAS DO CONSU- MODE FLORES E PLANTAS ORNAMENTAIS NO MERCADOINTERNOBRASILEIRO}

O mercado mundial de flores e plantas ornamentais está, atualmente, avaliado em $\bullet 75$ bilhões anuais, sendo que, deste total, $\bullet 60$ bilhões advêm do setor de flores e plantas, $\bullet 14$ bilhões do mercado de mudas e o restante da produção e circulação de bulbos (VLIET, $2005^{18}$ ). O fluxo no comércio internacional dos produtos da floricultura, por sua vez, está estimado em US\$ 9,4 bilhões anuais, hoje concentrados em países como a Holanda, Colômbia, Itália, Dinamarca, Bélgica, Quênia, Zimbábue, Costa Rica, Equador, Austrália, Malásia, Tailândia, Israel, EUA (Havaí) e outros. Nesse total, as flores e botões cortados frescos representam, em média, 49,5\%; plantas ornamentais, mudas e bulbos, $42,3 \%$ e as folhagens, folhas e ramos cortados frescos, $8,2 \%$ (JUNQUEIRA e PEETZ, 2004).
Trata-se de um mercado altamente concentrado, com a Holanda representando, isoladamente, pouco mais de $48 \%$ de toda a movimentação internacional. O segundo colocado, a Colômbia, já fica com apenas pouco mais de $6 \%$ de participação. O restante do mercado é disputado entre aproximadamente outros 100 países que participam do fluxo internacional de flores e plantas ornamentais.

Devido às mais diversas condicionantes socioeconômicas, culturais, geoclimáticas e ecológicas, o índice do consumo per capita de flores e plantas

A discussão das principais características e dos diferentes potenciais de crescimento do consumo de flores e plantas ornamentais no mercado externo apóia-se, inicialmente, numa importante segmentação, baseada especialmente nas diferenças quanto às condições socioeconômicas dos diversos países e continentes. A tabela 11 resume três importantes segmentos do mercado mundial.

No âmbito do mercado mundial, segundo avaliações do Flower Council of Holland (VLIET, 2005 $2006^{19}$ ), as principais tendências hoje delineadas quanto ao futuro da produção e da distribuição de flores e plantas ornamentais são as seguintes:

a) maior diferenciação nos produtos, embalagens, processos e apresentação, na busca da inovação como fator primordial de crescimento, conquista e manutenção das posições comerciais no mercado (market share);

b) forte pressão nos mercados tradicionais para a permanente redução dos preços, aumento da qualidade e das facilidades e constância do suprimento;

c) produção em deslocamento crescente para países de menores custos de produção;

d) consumo centrado no Hemisfério Norte; produção centrada no Hemisfério Sul;

e) crescimento nos tamanhos e portes econômicos das empresas de produção e distribuição;

f) crescimento do consumo de flores de corte em $14 \%$ nos próximos cinco anos; concentrado no Leste Europeu, USA e Ásia;

Tabela 8. Faturamento das floriculturas on-line no Brasil, em milhões de reais, 2001-2005

Table 8. On- line flowers sales in Brazil, 2001-2005 (R\$ million)

\begin{tabular}{cc}
\hline $\begin{array}{c}\text { Ano } \\
\text { Year }\end{array}$ & $\begin{array}{c}\text { Faturamento anual } \\
\text { Annual } \\
\text { (R\$. milhões) }\end{array}$ \\
\hline 2001 & 1,4 \\
2004 & 30,0 \\
$2005^{(20)}$ & 39,0 \\
\hline
\end{tabular}

Fonte: BRANCHER ${ }^{20}$ (2005)

\footnotetext{
${ }^{18}$ Op. cit.

VLIET, C.V. Flower Counciul of Holland. Floriculture Inernational Market. Palestra apresentada no Seminário sobre Certificação de Flores e Plantas, Holambra (SP), jun. 2006

Estimativas.

BRANCHER, M.D.R. Comércio eletrônico: uma nova realidade no varejo da floricultura do Brasil. Palestra apresentada no Congresso Fiaflora Expogarden Brasília 2005 de Floricultura, Brasília, 26 e 27 de maio de 2005.
} 
g) a Holanda continuará sendo o centro logístico, distribuidor, comercial e formador de tendências mundiais;

h) Crescimento da participação do auto-serviço no abastecimento global do mercado.

\section{TENDÊNCIAS, PERSPECTIVAS E DESAFIOS NA CADEIAPRODUTIVADAFLORICULTURANO BRASIL}

Os profissionais da cadeia produtiva da floricultura brasileira terão que ajustar seus projetos e empreendimentos à realidade de uma nova conjuntura econômica e social, que, tanto no Brasil quanto no resto do mundo, apresenta novas e inexoráveis exigências. É importante observar que os mercados consumidores estão mudando e que estas tendências são irreversíveis. Dessa forma, produtores, comerciantes atacadistas e varejistas e fornecedores terão que se adaptar a um mercado de pressão contínua para a baixa de preços e aumento geral da qualidade, dos padrões de apresentação, de logística de distribuição e de agregação de valores ao produto final. Além disso, serão exigidos grande potencial de inovação, diversificação e incorporação permanente de novos itens na oferta de produtos e na prestação de serviços, na qualidade de atendimento e no relacionamento com a clientela.

No âmbito dessas novas demandas, a vida associativa, institucional e corporativa poderá representar um dos mais importantes diferencias na carreira daqueles que tenderão a buscar efetivas soluções para os seus problemas, tanto no campo econômico quanto técnico, político e social. $\mathrm{O}$ fortalecimento dos órgãos e entidades de representação setorial, como o Instituto Brasileiro de Floricultura e Câmara Setorial da Cadeia Produtiva de Flores e Plantas Ornamentais, será de fundamental importância na gestão e encaminhamento de buscas de soluções concretas para problemas comuns. Parte importante das dificuldades que aparecerá para os profissionais vão necessitar de agregação de forças, de governança, de ações cooperativas e de esforços convergentes.

Um aspecto particularmente relevante, nesse novo cenário, será o fato de que os floricultores brasileiros passarão a conviver, de forma definitiva, com uma nova realidade na Cadeia Produtiva de Flores e Plantas Ornamentais no País: o surgimento e a consolidação de novos pólos regionais de produção, comércio, distribuição e consumo. Esse fenômeno - fundamental na redistribuição dos benefícios do crescimento e fortalecimento da economia da floricultura - resultará numa maior diversificação do consumo, com introdução de espécies e cultivares mais adaptadas aos gostos e às culturas regionais; na diminuição do papel centralizado, hoje ocupado pelos pólos produtivos paulistas, especialmente de Holambra e Campinas, que continuarão, no entanto, exercendo total liderança setorial, tanto nos aspectos estritamente comerciais quanto institucional e político. Além disso, influenciará na otimização dos custos logísticos de transporte e movimentação de mercadorias, condicionando maior diversificação e incorporação das produções regionais, especialmente no caso das plantas envasadas, mais volumosas, de alta cubagem e baixa relação custo $\mathrm{x}$ benefício nas operações comerciais de larga distância, entre outros.

Os principais desafios que compõem o novo cenário para os empresários da floricultura brasileira podem ser resumidos nas seguintes demandas e necessidades principais (Cf. JUNQUEIRA e PEETZ, 2005b, 2006a):

a) impulsionar o crescimento do consumo, de maneira permanente e sustentável para garantir o escoamento da produção crescente em todo o País;

b) rearranjar a base produtiva que, apoiada por governos e órgãos de fomento e promoção, seguirá a tendência de regionalização e fortalecimento em novos pólos produtivos por todo o País, levando a alterações extremamente significativas em termos de fluxos de abastecimento, tipificação de consumo, especializações de mercados, surgimento de novos agentes e eliminação de produtores menos adaptados dos pólos tradicionais;

c) intensificar os processos da abertura e acesso a novos mercados, bem como de alteração nas rotas e fluxos tradicionais de abastecimento, como decorrência das alterações da base produtiva e do aumento da concorrência entre regiões, países e canais de distribuição;

d) Inovar, especializar e segmentar. Nas relações comerciais contemporâneas, qualidade e padronização já não são diferenciais, mas, sim, itens obrigatórios. A permanência e o sucesso na atividade passam agora a ser ditados mais pela capacidade de inovação em tecnologias, produtos e serviços ao mercado consumidor. A segmentação, especialização e regionalização dos mercados consumidores serão fenômenos que tenderão a se acentuar rapidamente. Os produtores deverão analisar cuidadosamente a sua inserção atual e avaliar as suas metas futuras com muito critério, discernimento e objetividade, redefinindo focos, prioridades e novas parcerias, conforme os mercados que pretende atingir e os canais com os quais pretende atuar;

e) profissionalizar a distribuição, pois os produtores deverão apoiar e trabalhar pró - ativamente no fortalecimento, profissionalização e especialização dos canais de distribuição de atacado e varejo, buscando o favorecimento das ações cooperativas e/ou consorciadas, a conquista e preservação do seu poder de barganha nas negociações e a sua crescente participação no fluxo de troca de informações com a clientela final;

f) rever e adequar custos, pois os preços finais serão, cada vez mais, ditados pelo cliente no mercado. Esse será o teto a partir do qual o produtor terá que refazer, ao revés, os caminhos dos seus processos produtivos e comerciais, revendo, cortando e adequando custos e margens econômicas e financeiras. A presença permanente no mercado, o estudo criterioso do comportamento e das alterações nos hábitos e preferências dos consumidores e o uso de ferramentas de suporte como softwares de controle de custos, adquirem importância capital no mercado da floricultura profissional; 
g) fortalecer o varejo de auto-serviços, enquanto fenômeno particularmente importante porque acarretará profundas alterações nas relações de poder de barganha entre produtores e distribuidores, na governança da Cadeia Produtiva e na sobrevivência de um grande número de lojas do pequeno varejo tradicional;

h) fortalecer as ações associativistas, pois a complexidade e abrangência das ações necessárias farão com que o produtor tenha, cada vez menos, capacidade de atuar isoladamente no mercado e encontrar a adequada solução para os seus problemas. $\mathrm{O}$ fortalecimento das associações, cooperativas, órgãos e entidades de apoio institucional, de promoção e defesa dos interesses da categoria passam a ser, nesse sentido, fundamentais e decisivas;

i) prover atenção total ao cliente, já que o diferencial entre o sucesso e o fracasso dos empreendimentos produtivos e comercias será, cada vez mais, definido pela satisfação, atendimento e encantamento dos clientes finais. A capacidade de prever e superar as expectativas do consumidor no mercado deixa de ser uma responsabilidade apenas das áreas de comercialização e marketing e passa a integrar o universo de preocupações também do produtor, desde o momento da escolha das variedades, espécies e embalagens, até nos tratamentos e tecnologias de pós-colheita, visto que a durabilidade das flores e plantas ornamentais é, hoje, um dos mais influentes fatores de decisão na escolha e compra das mercadorias;

j) promover comercialmente a floricultura e o aumento do consumo per capita de flores e plantas ornamentais no Brasil, com a colaboração de entidades de classe, governamentais e instituições de apoio e fomento, como a única maneira eficiente e eficaz de encontrar vazão para a crescente produção interna.

k) Incrementar as exportações, pela superação dos entraves logísticos, burocráticos e tributários atuais, bem como da maior profissionalização dos produtores e agentes exportadores. Neste campo, destacam-se entre as iniciativas mais desejáveis: instalação de câmaras frias nos aeroportos, melhoria no funcionamento dos corredores de exportação, respeito à legislação de cultivares, rígidos controles fitossanitários em estrito respeito às normas internacionais, proteção às plantas ameaçadas de extinção, credenciamento de agentes para atuação nos pontos de entrada e saída de mercadorias, de modo controlar vetores e pragas e a melhoria geral do sistema de informação de mercado (BUAINAIN e BATALHA, 2007).

\section{CONSIDERAÇÕES FINAIS}

O mercado interno de flores e plantas ornamentais no Brasil deve ser entendido no contexto dos padrões de consumo dos países em desenvolvimento, nos quais, como foi visto, predominam as seguintes características principais compartilhadas com outras nações da América Latina, Ásia e África: a) baixo índice de consumo per capita; b) mercado com pequeno número relativo de compradores freqüentes; c) compras centradas em produtos bastante tradicionais; d) forte concentração sazonal da demanda em datas especiais e comemorativas, como Dia das Mães, Finados, Namorados, entre poucas outras.

Entre as tendências mais marcantes para a próxima década, citam-se as seguintes previsões: a) descentralização produtiva, com a consolidação e fortalecimento de pólos regionais; b) maior diversificação do consumo, com introdução de espécies e cultivares mais adaptadas aos gostos e às culturas regionais; d) diminuição do papel centralizado hoje ocupado pelos pólos produtivos paulistas, especialmente de Holambra e Campinas, que continuarão, no entanto, exercendo total liderança setorial, tanto nos aspectos estritamente comerciais, quanto institucional e político; e) maior otimização dos custos logísticos de transporte e movimentação de mercadorias, condicionando maior diversificação e incorporação das produções regionais, especialmente no caso das plantas envasadas, mais volumosas, de alta cubagem e baixa relação custo $\mathrm{x}$ benefício nas operações comerciais de larga distância; f) crescimento das vendas no canal supermercadista e pelo varejo on line. (JUNQUEIRA e PEETZ, 2005a, 2006 b).

Ressalta-se que o fortalecimento do comércio dos produtos da floricultura brasileira, tanto no âmbito do mercado interno quanto para o exterior, constitui-se em uma ação absolutamente vital para a garantia de um grande número de empregos, tanto no meio rural quanto nas cidades e, mesmo, para a sobrevivência de inúmeras propriedades e empresas agrícolas. Representa, desta forma, uma alternativa altamente eficiente e eficaz para o desenvolvimento econômico e social sustentável e equânime entre as diversas macrorregiões geográficas do País. 

SOCIOECONÔMICA RECENTE

Tabela 9. Consumo per capita anual de flores de corte em países selecionados, em 2005 (em euros) Table 9. Annual consumption of cut flowers per capita in selected countries, 2005 (euros)

\begin{tabular}{cc}
\hline Países selecionados & $\begin{array}{c}\text { Consumo per capita/ano } \\
\text { Annual consumption per capita }\end{array}$ \\
\hline Suíça / Switzerland & 94 \\
Holanda / Netherlands & 60 \\
Noruega / Norway & 58 \\
Áustria / Austria & 44 \\
Bélgica/ Belgium & 44 \\
Reino Unido / United Kingdom & 40 \\
Alemanha / Germany & 38 \\
Suécia / Sweden & 34 \\
Itália / Italy & 33 \\
França/ France & 33 \\
Irlanda / Ireland & 31 \\
EUA / United States of America & 26 \\
Espanha / Spain & 19 \\
México / Mexico & 10 \\
Polônia / Poland & 7 \\
Brasil / Brazil & 5 \\
Rússia / Russia & 3 \\
China / China & $<0,25$ \\
\hline
\end{tabular}

Fonte: Flower Council of Holland, apud VLIET $\left(2005,2006^{19}\right.$ ), exceto para o Brasil

Tabela 10. Consumo per capita anual de flores em vasos, em países selecionados, em 2005 (em euros) Tabela 10. Annual consumption of pot plants per capita in selected countries, 2005 (euros)

\begin{tabular}{cc}
\hline Países selecionados & $\begin{array}{c}\text { Consumo per capita/ano } \\
\text { Annual consumption per capita }\end{array}$ \\
Selected countries & 46 \\
Alemanha / Germany & 42 \\
Suíça/ Switzerland & 33 \\
Holanda / Netherlands & 20 \\
França / France & 12 \\
Reino Unido / United Kingdon & 10 \\
Itália / Italy & 10 \\
Espanha / Spain & 3 \\
Polônia / Poland & $<1$ \\
Rússia / Russia & \\
\hline
\end{tabular}

Fonte: Flower Council of Holland, apud VLIET $\left(2005^{22}, 2006^{22}\right)$.

\footnotetext{
${ }^{22}$ Op. cit.
} 
Tabela 11. Principais características do consumo de flores e plantas ornamentais, segundo estágio do desenvolvimento sócioeconômico dos diversos países no mercado mundial, em 2005

Table 11. Main consumption characteristics of flowers and ornamental plants, in different countries in world-wide market, 2005

\begin{tabular}{cc}
\hline $\begin{array}{c}\text { Grupo de países por } \\
\text { estágio de desenvolvimento } \\
\text { dos seus mercados } \\
\text { Groups of countries } \\
\text { by development } \\
\text { stages of their Markets }\end{array}$ & Principais características do consumo \\
\hline Main consumption characteristics \\
Países com mercados \\
emergentes \\
Emerging market \\
Baixo índice de consumo per capita; \\
Low per capita consumption; \\
Pequeno número relativo de compradores; \\
Low percentage of buyers; \\
Oferta centrada em produtos tradicionais; \\
Tradicional assortment; \\
Consumo centrado em ocasiões especiais (Dia das \\
Mães, Dia dos Namorados, Dia Internacional da \\
Mulher, Finados, outros). \\
Special occasions of consumption (Mother Day, \\
Valentine's Day, Women's Day, Weddings, Funerals \\
etc.)
\end{tabular}

Forte crescimento nos índices de consumo per capita; Strong growth of per capita consumption;

Crescimento do número relativo de compradores;

$$
\text { Growth percentage buyers; }
$$

Países com mercados

Consumidores procuram mais do que os produtos tradicionais;

em franco crescimento

Growth market

Consumer wants to have more choice than the traditional;

Mais oportunidades e ocasiões de consumo para presentear (aniversários, visitas, fins-de-semana,

$$
\text { Natal e outros); }
$$

More gift occasions are developing (birthday, easter,

Christmas, visits, Friday Bouquet etc.)

Aumento do consumo pessoal.

Increase personal consumption.

Países com mercados saturados

Saturated market
Crescimento mínimo, saturação e até decréscimo de consumo;

Minimal growth in consumption or even stagnation or decrease;

Flores para todo mundo, todos os dias;

Flowers for everybody, every day;

Mais interesse em inovações e novidades;

Much interest in innovation of assortment;

Todas as novas tendências no uso de flores e plantas são relevantes (decoração de interiores, estilo de vida e outras).

Trends in flowers and plants are important (Interior decoration and personal style).

Fonte: JUNQUEIRA e PEETZ, a partir de VLIET $\left(2005^{23}, 2006^{23}\right)$.

\footnotetext{
${ }^{22}$ Op. cit.
} 


\section{REFERÊNCIAS}

ANUÁRIO BRASILEIRO DAS FLORES 2007. Santa Cruz do Sul, RS: Editora Gazeta Santa Cruz, 2007.

AKI, A; PEROSA, J.M.Y. Aspectos da produção e consumo de flores e plantas ornamentais no Brasil. Revista Brasileira de Horticultura Ornamental, Campinas, v.8, n.1/2, p.13-23, 2002.

BONGERS, F.J.G. A distribuição de flores e plantas ornamentais e o sistema eletrônico integrado de comercialização. Revista Brasileira de Horticultura Ornamental, Campinas, v.8, n.1 / 2, p.49-56, 2002.

BRAINER, M.S.C.P.; OLIVEIRA, A.A.P. Floricultura: perfil da atividade no nordeste brasileiro. Fortaleza: Banco do Nordeste do Brasil, 2007. (Série Documentos do ETENE, n.17).

BRASIL (Governo). Ministério da Agricultura, Pecuária e Abastecimento - MAPA. Revista Brasileira de Horticultura Ornamental. Contribuições das Câmaras Setoriais Temáticas à Formulação de Políticas Públicas e Privadas para o Agronegócio. Revista Brasileira de Horticultura Ornamental, Campinas, v.13, n.1, p.3-12, 2007.

BRASIL (Governo). Ministério do Desenvolvimento, Indústria e Comércio Exterior. Secretaria de Comércio Exterior - SECEX, ALICE. Sistema de Informações do Comércio Exterior do Brasil, vários anos.

BUAINAIN, A. M.; BATALHA, M.O. (coord.). Cadeia produtiva de flores e mel. Brasília: IICA: MAPA/SPA, 2007 (Agronegócios; v.9).

CAMPINAS (Município). Centrais de Abastecimento de Campinas S/A. Estatísticas de Comercialização do Mercado Permanente de Flores e Plantas Ornamentais, 2000 a 2006.

CASTÃN, J.; FOGAÇA, L.A.; STEIN, M.N.; OTTMANN, M.M.A. Flora Catarina: uma história da nossa floricultura. Joinville: Soluções e Informática, 2006. 100 p.il.

CASTRO, C.E.F. Cadeia produtiva de flores e plantas ornamentais. Revista Brasileira de Horticultura Ornamental. Campinas, v.4, n.1/2, p.1-46, 1998.

COMPANHIA DE ENTREPOSTOS E ARMAZÉNS GERAIS DE SÃO PAULO - CEAGESP: Séries estatísticas de comercialização no Mercado de Flores e Plantas Ornamentais, vários anos.

CROMBERG, V.U.; CARLETTI, J. Perspectiva do mercado de flores e plantas ornamentais no Brasil. Agrianual 2001. São Paulo: FNP, 2001. p.337-348.

CROMBERG, V.U. Flores: a quem o produtor deve ouvir para suas decisões. Agrianual 2002. São Paulo: FNP, 2002. p.353-354.

DAUDT, R.H.S. Censo da produção de flores e plantas ornamentais no Rio Grande do Sul/Brasil na virada do milênio. 2002. 86 p. (Dissertação de Mestrado em Fitotecnia) - Faculdade de Agronomia da Universidade Federal do Rio Grande do Sul, Rio Grande do Sul, 2002.

ESPÍRITO SANTO (Governo do Estado). Secretaria de Estado da Agricultura, Abastecimento, Aqüicultura e Pesca.
Plano Estratégico da Agricultura Capixaba: Plano Estratégico de Desenvolvimento da Floricultura do Estado do Espírito Santo (PEDEAG-FLORICULTURA), 2004. Disponível em: <http://www.seag.es.gov.br/ floricultura.htm.> Acesso em 28 de jul.2006.

GRAZIANO, T. T. (Coord.). Relatório do Diagnóstico da Produção de Flores e Plantas Ornamentais Brasileira. Relatório Ibraflor/APEX, 2002. CD-Rom.

INSTITUTO BRASILEIRO DE FLORICULTURA (IBRAFLOR). Desenvolvimento recente da floricultura no Brasil. Campinas, São Paulo, 25p, 2004. Disponível em: <http://www.ibraflor.com.br>Acessado em 01 jul.2006.

FRANCISCO, V.L.F.S.; PINO, F. A.; KIYUNA, I. Floricultura no Estado de São Paulo. Informações Econômicas, São Paulo, v. 33, n.3, p.17-32, mar. 2003a.

FRANCISCO, V.L.F.S.; PINO, F. A.; KIYUNA, I. Os floricultores no Estado de São Paulo. Informações Econômicas, São Paulo, v.33, n.12, p.74-80, dez. 2003b.

FUNDAÇÃOINSTITUTOBRASILEIRODEGEOGRAFIA EESTATÍSTICA(IBGE). Caracterização do setor produtivo de flores e plantas ornamentais no Brasil, 1995-1996. Rio de Janeiro: IBGE, 2004. (Estudos e Pesquisas, informação econômica, n.2).

JUNQUEIRA, A. H. e PEETZ, M. S. Plano Estratégico das Exportações de Flores e Plantas Ornamentais do Brasil. Potencial Exportador da Floricultura Brasileira. Campinas: Ibraflor/ APEX-Brasil-FloraBrasilis. 2004. 1 CD-Rom.

JUNQUeIRA, A. H.; PEETZ, M. S. Perfil da Cadeia Produtiva de Flores e Plantas Ornamentais do Distrito Federal. Brasília: SEBRAE/DF. (Edição SEBRAE), 121 p., 2005 .

JUNQUEIRA, A. H.; PEETZ, M. S. Visão global: a cadeia produtiva de flores e plantas ornamentais no Brasil caminha a passos largos na implantação de um padrão internacional de gestão. Revista Cultivar HF, Pelotas, Ano VI, n.34, p.38, outubro/ novembro 2005b.

JUNQUEIRA, A. H. PEETZ, M. S. As flores brasileiras em 2007. Tecnologias de Produção HFF \& Citrus, Santo Antonio de Posse, SP, Ano III, 17/18.ed., p. 26-30, especial dez. 2006a.

JUNQUeIRA, A.H.; PEETZ, M. S. Perfil da Cadeia Produtiva de Flores e Plantas Ornamentais da Mesorregião Metropolitana de Belém. Belém: SEBRAE/ PA, 2006. Disponível em: <http:// www.biblioteca.sebrae.com.br/bds/BDS.nsf/ 4F8048F06CA79B 1F03257222004FB603/\$File/ NT000B5D02.pdf.> Acesso em 01 jul.2006b.

JUNQUEIRA, A. H. e PEETZ, M. S. Inteligência Comercial no Mercado de Flores. Palestra apresentada no Seminário Setorial Mercado de Flores da $14^{\mathrm{a}}$ Semana Internacional da Fruticultura, Floricultura e Agroindústria - FRUTAL / Flor Brazil 2007. Fortaleza, CE, 15 a 18 de setembro de 2007a. 1 CD-Rom.

JUNQUEIRA, A. H. e PEETZ, M. S. Producción y comercialización de plantas ornamentales en Brasil. Horticultura Internacional, Tarragona, Espanha, ano XIV, n.55, p.16-19, jan.2007b. 
JUNQUEIRA, A. H. e PEETZ, M. S. Exportações de flores e plantas ornamentais superam US\$35 milhões em 2007: recorde e novos desafios para o Brasil - Análise conjuntural da evolução das exportações de flores e plantas ornamentais do Brasil no período de janeiro a dezembro de 2007. São Paulo, 2008. Disponível em: <http:// www.hortica.com.br>. Acesso em 13 fev.2008.

KIYUNA, I. et al. A floricultura brasileira no início do século XXI: o perfil do produtor. Revista Brasileira de Horticultura Ornamental, Campinas, v.8, n.1/2, p.57-76, 2002a.

KIYUNA, I. et al. Estimativa do valor de mercado de flores e plantas ornamentais do Estado de São Paulo, 2001. Informações Econômicas, São Paulo, v.32, n.5, maio de $2002 \mathrm{~b}$.

MONTEJANO, J.L. Venda de flores e plantas no segmento de auto-serviços. Informativo Ibraflor, Campinas, Ano XI, n.45, p.3, agosto-setembro de 2005.

OPITZ, R. e BOQUADI. M.M. (Org.). Diretrizes da Câmara Setorial da Cadeia Produtiva de Flores e Plantas Ornamentais. In: VILELA, D; ARAÚJO, P.M.M. (Org.). Contribuições das Câmaras Setoriais Temáticas à Formulação de Políticas Públicas e Privadas para o Agronegócio. Brasília: MAPA/SE/SGAC, p.195-209, 2006.
RIO DE JANEIRO (Governo do Estado). Empresa de Assistência Técnica e Extensão Rural - EMATER. Censo da Floricultura do Estado do Rio de Janeiro 2002/2003. Niterói: EMATER, 2004. 1 CD-Rom.

SERVIÇO DE APOIO ÀS MICRO E PEQUENAS EMPRESAS NO ESTADO DEALAGOAS-SEBRAE/AL. Floricultura. Disponível em: <http://www.al.sebrae.com.br/ programas-projetos/default.asp>.Acesso em 27 out.2004.

SERVIÇO DE APOIO ÀS MICRO E PEQUENAS EMPRESAS NOESTADODEPERNAMBUCO-SEBRAE / PE. Diagnóstico da floricultura pernambucana. In Floricultura em Pernambuco, Recife (Edição SEBRAE, Série Agronegócio), 84p., 2002.

SERVIÇO DE APOIO ÀS MICRO E PEQUENAS EMPRESAS NOESTADODORIODEJANEIRO-SEBRAE / RJ. Diagnóstico da Cadeia Produtiva de Flores e Plantas do Estado do Rio de Janeiro. Rio de Janeiro: SEBRAE/ RJ, maio de 2003. Disponível em: <http://201.2.114.147/bds/ BDS.nsf/8104AA054E31F117832572290065B9F4/\$File/ NT000B5F32.pdf >Acesso em 7 jun.2007. 